\title{
The Effect of Clinical Pathway Implementation on Healing of Post Lower Limb Amputation for Diabetic Patients
}

\author{
Eman Fathy Amr Mohammed Aly, Teacher \\ Technical Nursing Institute, Faculty of Medicine, Alexandria University \\ Sanaa Mohammed Ahmed Alaa El-din, Professor \\ Medical Surgical Nursing, Faculty of Nursing, Alexandria University \\ Mamdouh Mohammed Kotb, Professor \\ Vascular Surgery, Faculty of Medicine, Alexandria University \\ Kawther Gaber Mohammed Tolba, Professor \\ Medical Surgical Nursing, Faculty of Nursing, Alexandria University \\ Wafaa Nour Ahmed Besely, Lecturer \\ Medical Surgical Nursing, Faculty of Nursing, Alexandria University
}

\begin{abstract}
Diabetic lower limb amputation remains the serious outcome of diabetic foot complications. It has been consistently shown that the best results of diabetic stump care occur when clinical pathway lan interdisciplinary approach is taken toward treatment. Objective: To determine the effect of implementing a clinical pathway on healing of post lower limb amputation for diabetic patients. Settings: The study was carried out in the Vascular Unit, Department of Surgery at the Alexandria Main University Hospital and the Private Alexandria Vascular Center (AVC) using a quasi experimental research design. Subjects: The study included 40 adult diabetic patients undergoing first exposure to unilateral lower limb amputation and free from vital organ failure. Study subjects are randomly divided into control and study groups (20 patients each). Tools: Three tools were used for data collection; Perioperative Diabetic Lower Limb Amputation Assessment, Clinical Pathway Variances Observation Checklist and Patients' Satisfaction Scale. Results: The study implies statistical significant difference in favor of the study group regarding wound healing during the second to the sixth week in postoperative follow up period. The results also imply that the study group had significantly higher satisfaction level as compared to the control one. Conclusion: Diabetic patients underwent lower limb amputation exhibited significantly better post clinical pathway health outcomes comparing with control one. Recommendations: Applying the clinical pathway for diabetic patients undergoing lower limb amputation rather than the hospital routine care is recommended.
\end{abstract}

Keywords: Clinical Pathway, Healing, Amputation, Diabetes.

\section{Introduction}

The long term sequel of diabetes mellitus (DM) is the microvascular and macrovascular complications that target end organs: the eyes, kidneys, heart, blood vessels and nerves ${ }^{(1)}$. Among the complications of DM are foot problems, the most common cause of non-traumatic limb amputation. The feet of people with DM can be affected by neuropathy, peripheral vascular disease, ulcers, infections, gangrene, and foot deformity ${ }^{(2)}$. Diabetic neuropathy affects up to $60 \%$ of individuals with DM and it is one of the most complex and potentially catastrophic of all the 
diabetic complications. Peripheral vascular disease has been implicated in foot ulceration in diabetes, but it may play a greater role in problems ultimately necessitating lower limb amputation ${ }^{(3)}$. Of all people with diabetes, $15-25 \%$ develops a diabetic foot ulcer at some time in their lives, these ulcers approximately precedes $85 \%$ of non-traumatic amputations ${ }^{(4)}$. Impaired blood flow not only increases the likelihood of gangrene in existing foot ulcers, but also prevents their healing. Frequently, the proximal location of the arterial occlusion requires the surgeon to amputate above or below the knee to ensure proper healing ${ }^{(5)}$. Diabetic foot infections usually arises either in a skin as a consequence of peripheral neuropathy or in a wound caused by some forms of trauma. ${ }^{(6)}$. Progression of sensory deficits can cause destruction of cartilage of foot joints leading to foot deformity. This destruction results in loss of normal foot architecture, leaving the foot susceptible to an arthropathy known as Charcot's osteoarthopathy ${ }^{(7)}$.

Lower extremity amputations in people with diabetes are a major cause of morbidity and mortality and place a significant economic burden on society ${ }^{(8)}$. It is frequently the fear of amputation that compels the patient to seek medical attention when circulation problems in the leg are suspected. Amputation may be the end, the loss of a part, but it may also be the end of pain and a new beginning ${ }^{(9)}$.

Goals of post-amputation care are pain control, optimization of range of motion (ROM) and strength of both lower and upper extremity musculature. Promotion of stump healing is also among these goals. Moreover, equipment prescription, and continued patient education and emotional support are also important goals ${ }^{(10)}$. Because successful stump healing requires adequate blood and nutrients to be supplied to the site of wound, the overall health of the patient influences the outcome of the stump healing ${ }^{(11)}$.
As more patients are discharged from the acute care setting immediately to the home care setting much earlier in their recovery, more surgical stump care is delivered by patients, their families, and home care providers than by the hospital nurse. Early planning and teaching regarding stump care is standard precautions that have been considered for preparing the patient for continuity of care before discharge ${ }^{(12)}$. It has been consistently shown that the best results of diabetic stump care occur when clinical pathway /an interdisciplinary approach is taken toward treatment $^{(13)}$.

Clinical Pathways aim to improve, in particular, the continuity and coordination of care across different disciplines and sectors. Clinical Pathways have four main components: a timeline, the categories of care or activities and their interventions, intermediate and long term outcome criteria, and the variance record to allow deviations to be documented and analyzed. A variance is any mandatory or checked optional intervention that was not done ${ }^{(14)}$. It provides detailed guidance for each stage in the management of a patient. Moreover, it promotes quality of care; improve health care providers' communication and satisfaction $^{(15,16)}$.

Nurses have a key role in all aspects of clinical pathway development and use ${ }^{(17)}$. Nursing interactions with the patient and family involvement have a direct impact on recovery and rehabilitation ${ }^{(9,18)}$.

\section{Significance of the study}

Data generated from this study can lead to the improvement in patient's care and satisfaction through implementation of clinical pathway. It also ensures the consistency and quality of care, and decreases hospital stay as well as cost. 


\section{Aim of the Study}

The aim of this study is to determine the effect of the implementation of a clinical pathway on healing of post lower limb amputation for diabetic patients.

\section{Research Hypothesis:}

Patients on whom the clinical pathway is implemented exhibit faster healing and higher level of satisfaction after lower limb amputation than those on whom it is not implemented.

\section{Materials and Method}

\section{Materials}

Design: A quasi experimental design was used.

Settings: The study was conducted in two settings at Alexandria. The first setting was Alexandria Main University Hospital, the vascular unit at the surgical department. The second setting was the private Alexandria Vascular Center (AVC).

Subjects: A convenient sample of 40 adult diabetic patients undergoing lower limb amputation were sequentially recruited equally into 2 groups; study and control groups (20 patients each). An equal ten patients were taken from each hospital for study and control group. Twenty patients were assigned to receive care according to the clinical pathway (study group) and the rest were received conventional care (control group). Study subjects inclusion criteria were: Diabetic patients aged between 20- 60 years old, have first exposure to unilateral amputation, able to communicate and free from vital organ failure (renal, hepatic, cardiac).
Tools: The tools of the current study were:

Tool I: Perioperative Diabetic Lower Limb Amputation Assessment (PDLLAA)

It was developed by the researchers after extensive reviewing of the related literature (19-27) to assess comprehensive patients' status through the perioperative period for all subjects. This tool comprised two main parts:

Part I: Pre-post operative Diabetic Lower Limb Amputation Assessment: this part included patients' profile, medical data, diagnostic studies, assessment of patient's physical status, nursing interventions assessment, incisional pain and wound healing assessment.

Part II: Intra-operative Diabetic Lower Limb Amputation Assessment: it included date and time of operation, duration of operation, level of amputation, name and dose of used medications, type and amount of intravenous solutions, vital signs, presence of suture, drain, bleeding and discharge, type of the wound and dressing.

Tool II: Clinical Pathway Variances Observation Checklist Assessment (CPVA) Tool

This tool $^{(14,17)}$ aimed to measure variations of performance. Observations of performance were checked while care was rendering to patients. It was applied on the study group in a form of observational checklist related to the fifteen items of patients' care, categorized into four points Likert scale and ranged from zero to two with total score value ranged between 0-30, as following: two: done adequately, one: done inadequately and zero: not done. The not applicable item was out of score.

Tool III: Patients' Satisfaction Scale about Caring Process

This scale was adopted from Salisbury et $\mathrm{al}^{(24)}$, and translated to Arabic language and tested for validity and reliability by Abd ElAziz E. $(2011)^{(25)}$. It was applied to all study 
subjects and aimed to assess patients' satisfaction about the caring process that patient's received. Five point Likert scale ranged from 15 to 75 was used. From 15 to 26 considered very dissatisfied, dissatisfied: from 27 to 38 , neutral: from 39 to 50 and satisfied from 51 to 62 , very satisfied from 63 to 75 .

\section{Clinical Pathway Protocol (CPP):}

The clinical pathway protocol for diabetic patients undergoing lower limb amputation was developed by the researchers after extensive review of recent related literatures ${ }^{(28-38)}$. The clinical pathway protocol (CPP) starts with patients' profile, medical data, and major patient's goals in addition to the clinical pathway team's role.

\section{Method}

- Data was collected on eight months from June first 2013 to end January 2014. The purpose of the study was explained by the researcher to all patients included in the study.

- A written approval was obtained from the administrative personnel at the study settings. Informed consent was taken from patients to participate in the study.

- The clinical pathway protocol format was prepared in a matrix form that included ten vertical columns representing time intervals and fifteen horizontal rows representing patient's care items.

- The ten time intervals included the three perioperative stages: two intervals represent the preoperative stage (admission day and preoperative period), one interval represents the intraoperative stage (operative day) and seven intervals represent the postoperative stage (hospitalization period, and six weeks thereafter). The fifteen horizontal rows covering patient's assessment and total patient's care items as:

1- General assessment related to patient's profile and medical data

2- Vital signs assessment

3- Anthropometric measurements

4- Lower limbs assessment included circumference in centimeter at mid-thigh, neurological and vascular status, mobility, activity, wound healing, and pain.

5- Diagnostic studies: Blood glucose level, glycated hemoglobin, serum albumin, hemoglobin, complete blood cell count, urine test for glucose and ketone bodies, electrocardiogram , chest X-ray, Doppler ultrasound, bleeding and clotting times and angiography.

6- Medications as: insulin, antibiotic, analgesics, and others.

7- Psychological care

8- Health education for patient and family regarding details of plan of care

9- Surgical pain assessment and management

10-Phantom pain assessment and management

11-Wound assessment and dressing

12-Mobility and exercise

13-Prevention of complications as fall and trauma, hemorrhage, infection, stump contracture, skin break down, and edema

14-Control of blood glucose level

15-Discharge plan and follow up visits schedule 
- Content validity was done for the two developed tools and the clinical pathway protocol through submitting them to a 9 jury members: Six professors from Alexandria Faculty of Nursing, two professors from Vascular Surgery department and one from Anesthesia department.

- The reliability was done for clinical pathway protocol using Cronbach's alpha test $(\mathrm{r}=0.79)$.

- Reliability testing of tool three was carried out again for the Arabic version of patients satisfaction scale using Cronbach's alpha reliability test $(r=0.924)$.

- Pilot study: The feasibility and applicability of the four study tools were done on five patients before starting data collection and necessary modifications were done.

- Each patient in the study group received the routine care in addition to clinical pathway protocol.

- Evaluating the clinical pathway: it consisted of comparing the outcomes of both groups by using Tool one and Tool three in relation to stump healing, length of hospital stays, patients' satisfaction, mortality within 30 days post amputation, morbidity (general and wound complications), and readmission within 6 weeks.

- Variances from Clinical Pathway Protocol (CPP) observational checklist were observed and recorded using tool three.

\section{Ethical considerations:}

Confidentiality and privacy of patient's data were asserted. Participation in the study was voluntary, with the patient right to withdraw at any time.

\section{Statistical Analysis}

Data entry and statistical analysis were done using SPSS 14.0 statistical software package. Data were presented as descriptive statistics; comparison between groups of variables was by Chi-square test. Statistical significance was considered at $\mathrm{p}$ - value $<0.05$.

\section{Results}

Table (1) presents patients' profile of patients in both groups as, more than two thirds were between 50-60 years, almost equal number of illiterate or read \& write males and females, almost all were married, the highest percentages in both groups were not working or housewives and lived in rural area.

Table (2) presents medical data; regarding length of hospital stay, the majority $(70.0 \%)$ of the control group median hospital stay was nine days, while all patients in the study group median hospital stay was only four days. Significant statistical difference between both groups was found $(\mathrm{P}=0.000 *)$. About two-thirds $(65 \%)$ of patients in the control group had left lower limb amputation, while $(60 \%)$ of patients in the study group had right lower limb amputation, the majority $(80 \%$ and $65 \%$ ) of patients in the control and study groups were respectively have type II diabetes. All patients in the control and study groups received preoperative anesthesia assessment and informed consent. The hospital readmission within 6 weeks in the control group was $(55.0 \%)$ while in the study group it was $(15.0 \%)$. There was statistical significant higher hospital readmission in the control group than the study group $\left(\mathrm{P}=0.008^{*}\right)$. Five per cent of patients in control group and $10.0 \%$ of patients in study group had reamputation. General morbidity fall and trauma happened in small percentages in both control and study groups (10\% and 5\%) respectively. No skin break down was noticed in both groups. Regarding wound complications, hemorrhage occurred in $(35.0 \%)$ of patients 
in control group versus $(20.0 \%)$ of patients in study group. This table also shows that about two thirds of the control group showed wound edema and infection versus only $15 \%$ of the study group with significant statistical difference $\left(\mathrm{P}=0.001^{*}\right)$. No mortality within 30 days on both groups.

Table (3) shows intra-operative assessment, according to the level of amputation, the highest percentages $(40.0 \%$ and $30.0 \%$ ) in both control and study groups respectively had above knee amputation, while no patient had knee disarticulation. Regarding medications, all patients in both groups were given spinal anesthesia. The majority $(85.0 \%)$ were given normal saline. In relation to vital signs: the majority $(90.0 \%)$ in both control and study groups had normal ranges of temperature, pulse and respiration. All patients in both control and study groups had normal blood pressure ranges. All patients in both groups had closed and sutured wound, with presence of drain and soft dressing. There is no statistical significant difference between both groups as regards intra-operative assessment data.

Table (4) clarifies that the mean and standard deviation of each nursing interventions' areas that introduced to study group throughout the perioperative phases were much higher than control group. It can be noticed that there were statistical significant differences between control and study groups in every nursing interventions areas in all perioperative phases.

Table (5) illustrates stump healing which began in the second week of postoperative follow up period, this table shows statistical significant difference between the control and study groups $\left(\mathrm{P}=0.027^{*}\right)$. As regards stump healing during third week of postoperative follow up period, this table reveals statistical significant difference between the control and study groups $(\mathrm{P}=0.011 *)$ where Mean $\pm \mathrm{SD}=(13.4 \pm 4.2)$ in control group while Mean $\pm \mathrm{SD}=(8.5 \pm 2.9)$ in study group. According to stump healing during fourth week of postoperative follow up period, this table clarifies statistical significant difference between the control and study groups $(\mathrm{P}=0.001 *)$. In relation to stump healing during fifth and sixth weeks of postoperative follow up period, this table indicates statistical significant difference between the control and study groups $(\mathrm{P}=0.001 *) . \quad \mathrm{Mean} \pm \mathrm{SD}=(13.3 \pm 4.6) \quad$ in control group while Mean $\pm \mathrm{SD}=(8.4 \pm 3.1)$ in study group.

Table (6) explains the occurrence of Clinical Pathway Variances in the study group. Hundred per cent was done adequately in five items: general assessment, psychological care, health education, mobility \& exercises, and nursing interventions of altered sensory perception. Fifteen per cent was done inadequately in eight items: vital signs assessment, both lower limbs assessment, diagnostic studies, medications, dressing \& wound care, prevention of complications, control of blood glucose level and discharge plane \& follow up. The majority $85.0 \%$ was done adequately and (15.0\%) was not applicable, in one item: nursing interventions of surgical pain. $45.0 \%$ was done adequately, (20.0\%) was done inadequately and (35.0\%) was not applicable in one item: anthropometric assessment.

Table (7): presents the total patients' satisfaction with caring process, the total scores of the patients' satisfaction scale ranged from (27-45) and the mean \pm SD score was $(33.9 \pm 5.6)$ in the control group, while in the study group it ranged from (51$75)$ and the mean score was $(60.2 \pm 6.0)$. There was statistical significant difference between the mean scores of the control and study groups $\left(\mathrm{P}=0.000^{*}\right)$ in which the study group was more satisfied than the control group.

\section{Discussion}

The findings of the present study revealed no statistical significant differences in the basic data (patient's profile $\&$ medical 
data) between the control and study groups. The present study indicated that only half of patients in control group had subjected to neurological and vascular assessment at both intact and affected limb during preoperative period with no further assessment during postoperative and follow up periods. All patients in study group were assessed for neurological and vascular assessment at both intact and affected limb during: preoperative, postoperative and follow up periods. These results are in accordance with Judge ${ }^{(39)}$ who confirmed that to detect neurovascular deficits the nurse should carry out simple but regular neurovascular assessment, documenting findings and acting to minimize further damage.

In the present study, the result revealed that all patients in both groups were survived. Contrary to present findings, Leigheb $^{(40)}$ found that after the implementation of the clinical pathway, thirty days mortality rates had decreased when compared to the data before the pathway.

The findings of the current study showed no statistical significant differences between both groups as regards intraoperative assessment data. It means that the intraoperative interventions were in harmony between both control and study groups and the differences in outcomes might be due to pre and postoperative care.

Concerning stump healing, the findings revealed statistical significant differences in favor of the study group during the second to the six week of postoperative follow up period. The result of the present study may be owed to several factors as: diagnostic studies, wound complications, patients' adherence to medical regimen, and nursing interventions.

At first postoperative day, the majority of patients in control group were hyperglycemic versus less than one third of patients in study group with statistical significant difference between both groups.
This finding is supported by Berghe et al. ${ }^{(41)}$ who focused that hyperglycemia could influence perioperative mortality and morbidity by a number of mechanisms. Hyperglycemia interferes with the function of polymorph nuclear leukocytes predisposing to infection and may impair healing. Moreover, Fraser $^{(42)}$ confirmed that hyperglycemia could contribute to increased platelet activity and disordered coagulation and fibrinolytic function as well as abnormalities in lipid metabolism. Hyperglycemia might adversely affect endothelial function. Posthauer ${ }^{(43)}$ added that hyperglycemia decreases oxygen to the tissues. Delivery of leukocytes and antibiotic agents to the wound is impaired due to lack of blood flow. Oxygen is necessary for macrophage mobility and growth of granulation tissue during wound healing.

The results of the current study illustrated significant statistical difference between the control and study groups regarding wound edema and infection as about two thirds of the control group showed wound edema and infection versus only $15 \%$ of the study group. This is in agreement with Carson et al. ${ }^{(44)}$ who suggested a relation between improved glucose control in the perioperative period and lower rates of wound infection. In contrarily, Choong and Calland et al. ${ }^{(45,46)}$ found no differences in the occurrence of in-hospital or after-discharge wound complications between clinical pathway and control groups among patients with fractured neck of femur.

Concerning patients' adherence to medical regimen, the World Health Organization $(\mathrm{WHO})^{(47)}$, asserted that nonadherence to the medical regimen consists major clinical problems in the management of patients with chronic illness. Adherence is a multidimensional phenomenon determined by the interaction of five dimensions: social, provider-patient/health care system, condition-related, therapyrelated and patient-related factors $^{(48)}$. All 
these dimensions were considered in Clinical Pathway Protocol.

It is important to consider the holistic nursing interventions and educations given to the study group concerned with adjustment of blood glucose level, diet, medication, teaching the patient about stump care, prevention of complications and follow-up schedule beside psychological care. Appropriate attention was paid to stump care and sterile technique. Stump edema might be due to infection or surgical procedure as well as poor positioning as dangling of residual limb. This is in line with Dealey ${ }^{(49)}$ who suggested that when caring for patients with wounds, it is important to take a holistic approach, considering physical, psychological and spiritual care as they are inevitably linked. Therefore, nursing interventions encompass comprehensive neurological \& vascular assessments of both intact and affected extremities.

The results showed statistical significant decrease in the duration of hospitalization in the study group than the control one. The results of the current study are in agreement with many studies which concluded that using clinical pathway resulted in decreased length of hospital stay in other clinical problems ${ }^{(50-52)}$. On the other hand, El-Baz, Roberts's et al ${ }^{(53-55)}$ found that clinical pathway was associated with longer hospital stay. Beaupre and Sulch ${ }^{(56,57)}$ found no difference in total length of hospital stay (LOS) between control and clinical pathway groups. The results of present study revealed a statistical significant difference in favor of the study group regarding readmission.

This result could be explained in the light of the effect of clinical pathway which includes continuous assessment, ongoing health education for the patient and family, predetermined discharge plan and focused follow up. These results are in agreement with Global Institute for Emerging Healthcare Practices ${ }^{(58)}$ which found that surgical complications, such as infections, are associated with readmissions. On the other hand, the results are not in accordance with Abd El-Aziz, El Baz and Beaupre $^{(25,53,56)}$ who found that the implementation of clinical pathway did not decrease readmission rates.

The results of current study illustrated that study group had significantly higher satisfaction level as compared to the control one. These findings are congruent with Van Dam $^{(59)}$ who stated that, patients and their families reported satisfaction at having a specific consistent clinical pathway implemented by caregiver who provided information and guidance throughout caring. This is not approved with Jon et $\mathrm{al}^{(60)}$ who implemented a clinical pathway for inguinal hernia repair and found no statistically significant differences related to patients' satisfaction between the two comparison groups.

The results of the present study exhibited that all required care were done adequately in five items of $\mathrm{CP}$ which were: general assessment, psychological care, health education, mobility \& exercises, and nursing interventions of altered sensory perception. The results of the present study also revealed that nursing interventions for surgical pain was done adequately in $(85.0 \%)$ and $(15.0 \%)$ was not applicable because three patients had no pain. It might be due to neuropathy which is a complication of diabetes. Moreover, the results showed that only $45.0 \%$ of the study group patients intervention was done adequately, (20.0\%) was done inadequately and $(35.0 \%)$ was not applicable in one item which was anthropometric assessment (BMI). In this regard, Smith ${ }^{(61)}$ found that the practice variations were reduced significantly following implementation of the clinical pathway for radical prostatectomy and oncology patients. On the other hand, these results may be far away from Abbass $^{(62)}$ who found no variances in a clinical pathway of patients undergoing percutaneous coronary intervention. 


\section{Conclusion}

Diabetic patients underwent lower limb amputation exhibited significantly better post clinical pathway outcomes comparing with control one.

\section{Recommendations}

Based on the findings of the current study the following recommendations are suggested:

1- Apply the clinical pathway for diabetic patients undergoing lower limb amputation rather than the hospital routine care.

2- Provide vascular department with Arabic and English versions of the clinical pathway and be available for all health team personnel as well as patients.
3- Vascular department should be equipped with enough supportive aids commensurate with the patients' condition.

4- Training workshops and courses should be given for nurses about implementation of clinical pathway.

5- Evaluate lower limbs neurovascular condition for diabetic patients with amputation periodically, to determine high risk conditions for reamputation.

6- Study the nursing staff satisfaction after implementation of the clinical pathway for diabetic patients undergoing lower limb amputation.

7- Study the relationship between neurovascular assessment and diabetic reamputation. 
Table (1): Frequency distribution of Preoperative Assessment for Patients with Diabetic Lower Limb Amputation in control and study groups in relation to patients' profile

\begin{tabular}{|c|c|c|c|c|c|c|c|}
\hline \multirow{3}{*}{\multicolumn{2}{|c|}{ patients' profile }} & \multicolumn{4}{|c|}{$\begin{array}{c}\text { Groups } \\
\end{array}$} & \multirow{3}{*}{$\mathbf{X}^{2}$} & \multirow{3}{*}{$\mathbf{P}$} \\
\hline & & \multicolumn{2}{|c|}{ Control } & \multicolumn{2}{|c|}{ Study } & & \\
\hline & & No & $\%$ & No & $\%$ & & \\
\hline \multirow{2}{*}{ Age } & - $\quad 30-49$ & 6 & 30.0 & 7 & $\begin{array}{c}35.0 \\
\%\end{array}$ & \multirow{2}{*}{0.11} & \multirow{2}{*}{0.736} \\
\hline & - $50-60$ & 14 & 70.0 & 13 & $\begin{array}{c}65.0 \\
\%\end{array}$ & & \\
\hline \multicolumn{2}{|l|}{ Mean \pm SD } & \multicolumn{2}{|c|}{$51.8 \pm 9.2$} & \multicolumn{2}{|c|}{$49.7 \pm 9.6$} & $t=0.71$ & 0.483 \\
\hline \multirow{2}{*}{ Sex } & - $\quad$ Male & 11 & 55.0 & 10 & 50.0 & \multirow{2}{*}{0.10} & \multirow{2}{*}{0.752} \\
\hline & - Female & 9 & 45.0 & 10 & 50.0 & & \\
\hline \multirow{6}{*}{$\begin{array}{l}\text { Educational } \\
\text { Level }\end{array}$} & - illiterate & 7 & 35.0 & 4 & 20.0 & \multirow{6}{*}{4.3} & \multirow{6}{*}{0.508} \\
\hline & - $\quad$ Read \& write & 5 & 25.0 & 9 & 45.0 & & \\
\hline & - $\quad$ Primary & 2 & 10.0 & 0 & 0.0 & & \\
\hline & - Preparatory & 1 & 5.0 & 2 & 10.0 & & \\
\hline & - $\quad$ Secondary & 4 & 20.0 & 4 & 20.0 & & \\
\hline & - University & 1 & 5.0 & 1 & 5.0 & & \\
\hline \multirow{4}{*}{ Marital status } & - $\quad$ Single & 1 & 5.0 & 2 & 10.0 & \multirow{4}{*}{0.37} & \multirow{4}{*}{0.947} \\
\hline & - $\quad$ Married & 16 & 80.0 & 15 & 75.0 & & \\
\hline & - Divorced & 1 & 5.0 & 1 & 5.0 & & \\
\hline & - Widow & 2 & 10.0 & 2 & 10.0 & & \\
\hline \multirow{3}{*}{ Occupation } & - manual & 5 & 25.0 & 5 & 25.0 & \multirow{3}{*}{0.0} & \multirow{3}{*}{1.000} \\
\hline & - $\quad$ Professional & 6 & 30.0 & 6 & 30.0 & & \\
\hline & $\begin{array}{ll}\text { Not working } \\
\text { or housewives }\end{array}$ & 9 & 45.0 & 9 & 45.0 & & \\
\hline \multirow{2}{*}{ Residence } & - Urban & 4 & 20.0 & 4 & 20.0 & \multirow{2}{*}{0.0} & \multirow{2}{*}{1.000} \\
\hline & - $\quad$ Rural & 16 & 80.0 & 16 & 80.0 & & \\
\hline
\end{tabular}

$\mathrm{P}$ value based on Fisher exact probability

$\mathrm{t}$ : independent samples t-test. 
Table (2): Distribution of Perioperative Assessment for Patients with Diabetic Lower Limb Amputation in control and study groups according to their medical data

\begin{tabular}{|c|c|c|c|c|c|c|c|}
\hline \multirow{3}{*}{\multicolumn{2}{|c|}{ Medical data }} & \multicolumn{4}{|c|}{ Group } & \multirow{3}{*}{$\mathbf{X}^{2}$} & \multirow{3}{*}{$\mathbf{P}$} \\
\hline & & \multicolumn{2}{|c|}{ Control } & \multicolumn{2}{|c|}{ Study } & & \\
\hline & & No & $\%$ & No & $\%$ & & \\
\hline \multirow{4}{*}{$\begin{array}{l}\text { Length of hospital } \\
\text { stay (days) }\end{array}$} & - $2-6$ & 2 & 10.0 & 20 & 100.0 & \multirow{3}{*}{32.7} & \multirow{3}{*}{$0.000 *$} \\
\hline & - $7-13$ & 14 & 70.0 & 0 & 0.0 & & \\
\hline & . $14-20$ & 4 & 20.0 & 0 & 0.0 & & \\
\hline & Median (range) & \multicolumn{2}{|c|}{$9(5-20)$} & \multicolumn{2}{|c|}{$4(2-5)$} & $\mathrm{Z}=5.4$ & $0.000 *$ \\
\hline \multirow{2}{*}{ Affected limb } & - $\mathrm{Rt}$ & 7 & 35.0 & 12 & 60.0 & \multirow{2}{*}{2.5} & \multirow{2}{*}{0.113} \\
\hline & - $\mathrm{Lt}$ & 13 & 65.0 & 8 & 40.0 & & \\
\hline \multirow{2}{*}{ Type of diabetes } & - $\quad$ Type I & 4 & 20.0 & 7 & 35.0 & \multirow{2}{*}{1.1} & \multirow{2}{*}{0.288} \\
\hline & - Type II & 16 & 80.0 & 13 & 65.0 & & \\
\hline $\begin{array}{l}\text { Pre operative } \\
\text { anesthetic } \\
\text { assessment } \\
\end{array}$ & - Done & 20 & 100.0 & 20 & 100.0 & NA & NA \\
\hline Informed consent & - Done & 20 & 100.0 & 20 & 100.0 & NA & NA \\
\hline \multirow{2}{*}{$\begin{array}{l}\text { Readmission } \\
\text { within } 6 \text { weeks }\end{array}$} & - Yes & 11 & 55.0 & 3 & 15.0 & \multirow{2}{*}{7.0} & \multirow{2}{*}{$0.008 *$} \\
\hline & - $\mathrm{No}$ & 9 & 45.0 & 17 & 85.0 & & \\
\hline \multirow{2}{*}{$\begin{array}{l}\text { Reamputation } \\
\text { within } 6 \text { weeks } \\
\end{array}$} & - Yes & 1 & 5.0 & 2 & 10.0 & \multirow{2}{*}{ FEP } & \multirow{2}{*}{0.548} \\
\hline & - $\mathrm{No}$ & 19 & 95.0 & 18 & 90.0 & & \\
\hline \multirow{3}{*}{$\begin{array}{c}\text { General Morbidity } \\
-\quad \text { Fall \& } \\
\text { trauma } \\
\end{array}$} & & & & & & \multirow{3}{*}{ FEP } & \multirow{3}{*}{0.548} \\
\hline & - Yes & 2 & 10.0 & 1 & 5.0 & & \\
\hline & - $\quad \mathrm{No}$ & 18 & 90.0 & 19 & 95.0 & & \\
\hline $\begin{array}{l}\text { Skin break } \\
\text { down }\end{array}$ & - No & 20 & 100.0 & 20 & 100.0 & NA & NA \\
\hline \multirow{3}{*}{$\begin{array}{l}\text { Wound } \\
\text { complications } \\
\quad-\text { Hemorrhage }\end{array}$} & & & & & & \multirow{3}{*}{1.1} & \multirow{3}{*}{0.288} \\
\hline & - Yes & 7 & 35.0 & 4 & 20.0 & & \\
\hline & - $\quad$ No & 13 & 65.0 & 16 & 80.0 & & \\
\hline \multirow{2}{*}{ - Edema } & - Yes & 13 & 65.0 & 3 & 15.0 & 104 & $0.001 *$ \\
\hline & - No & 7 & 35.0 & 17 & 85.0 & 10.4 & $0.001 \%$ \\
\hline - Infe & - Yes & 13 & 65.0 & 3 & 15.0 & 104 & $0001 *$ \\
\hline - Intection & - $\quad$ No & 7 & 35.0 & 17 & 85.0 & & \\
\hline
\end{tabular}


Table (3): Intra-operative assessment of diabetic patients undergoing Lower Limb Amputation in both control and study groups

\begin{tabular}{|c|c|c|c|c|c|c|}
\hline \multirow{3}{*}{\multicolumn{2}{|c|}{ Intra-operative assessment }} & \multicolumn{4}{|c|}{ Group } & \multirow{3}{*}{ FEP } \\
\hline & & \multicolumn{2}{|c|}{ Control } & \multicolumn{2}{|c|}{ Study } & \\
\hline & & No & $\%$ & No & $\%$ & \\
\hline \multirow{5}{*}{ Level of amputation } & - Toe amputation & 3 & 15.0 & 6 & 30.0 & \multirow{5}{*}{0.611} \\
\hline & - Trans metatarsal & 2 & 10.0 & 3 & 15.0 & \\
\hline & - Below knee & 7 & 35.0 & 5 & 25.0 & \\
\hline & $\begin{array}{ll}\text { - } & \text { Knee } \\
& \text { disarticulation }\end{array}$ & 0 & 0.0 & 0 & 0.0 & \\
\hline & - $\quad$ Above knee & 8 & 40.0 & 6 & 30.0 & \\
\hline $\begin{array}{l}\text { Medications and Fluids } \\
-\quad \text { Anesthetic } \\
\text { medication }\end{array}$ & - Spinal & 20 & 100.0 & 20 & 100.0 & NA \\
\hline - Muscle relaxant & - Not given & 20 & 100.0 & 20 & 100.0 & NA \\
\hline - Other medications & - Not given & 20 & 100.0 & 20 & 100.0 & NA \\
\hline \multirow{2}{*}{ - IV solutions } & - $\quad$ Normal saline & 17 & 85.0 & 17 & 85.0 & \multirow{2}{*}{1.000} \\
\hline & - $\quad$ Saline \& ringers & 3 & 15.0 & 3 & 15.0 & \\
\hline \multirow[t]{3}{*}{ Vital sings } & & & & & & \multirow{3}{*}{1.000} \\
\hline & - Normal & 18 & 90.0 & 18 & 90.0 & \\
\hline & - Low grade fever & 2 & 10.0 & 2 & 10.0 & \\
\hline \multirow{2}{*}{ - Pulse } & - Normal & 18 & 90.0 & 18 & 90.0 & \multirow{2}{*}{1.000} \\
\hline & - Tachycardia & 2 & 10.0 & 2 & 10.0 & \\
\hline \multirow{2}{*}{ - Respiration } & - Normal & 18 & 90.0 & 18 & 90.0 & \multirow{2}{*}{1.000} \\
\hline & - Tachypnea & 2 & 10.0 & 2 & 10.0 & \\
\hline \multirow{2}{*}{ - Blood pressure } & - $\quad$ Normal & 20 & 100.0 & 20 & 100.0 & \multirow{2}{*}{1.000} \\
\hline & - $\quad$ Stage 1 & 0 & 0.0 & 0 & 0.0 & \\
\hline Type of wound & - Closed & 20 & 100.0 & 20 & 100.0 & NA \\
\hline Sutured wound & - $\quad$ Present & 20 & 100.0 & 20 & 100.0 & NA \\
\hline Drain & - $\quad$ Present & 20 & 100.0 & 20 & 100.0 & $\mathrm{NA}$ \\
\hline Type of dressing & - Soft & 20 & 100.0 & 20 & 100.0 & $\mathrm{NA}$ \\
\hline
\end{tabular}


Clinical Pathway on Healing of Diabetic Post Lower Limb Amputation

Table (4): Comparison between Pre-\&Postoperative Nursing Interventions of both Control and Study Groups for Diabetic Patients with Lower Limb Amputation

\begin{tabular}{|c|c|c|c|c|c|c|c|c|c|c|c|c|c|c|c|}
\hline \multirow{3}{*}{ Nursing interventions } & \multicolumn{4}{|c|}{$24 \mathrm{hrs}$ pre-operative } & \multirow{3}{*}{$P$} & \multicolumn{4}{|c|}{24 hrs post-operative } & \multirow{3}{*}{$\mathrm{P}$} & \multicolumn{4}{|c|}{ Sixth week post-operative } & \multirow{3}{*}{$P$} \\
\hline & \multicolumn{2}{|c|}{ Control } & \multicolumn{2}{|c|}{ Study } & & \multicolumn{2}{|c|}{ Control } & \multicolumn{2}{|c|}{ Study } & & \multicolumn{2}{|c|}{ Control } & \multicolumn{2}{|c|}{ Study } & \\
\hline & Mean & SD & Mean & SD & & Mean & SD & Mean & SD & & Mean & SD & Mean & SD & \\
\hline Psychological care & 7.4 & 19.5 & 94.5 & 4.4 & $0.000^{*}$ & 15.7 & 26.4 & 98.3 & 3.1 & $0.000 *$ & 5.0 & 8.9 & 96.5 & 5.5 & $0.000 *$ \\
\hline Health education & 7.8 & 11.9 & 96.6 & 2.6 & $0.000^{*}$ & 13.7 & 12.7 & 98.0 & 4.0 & $0.000^{*}$ & 6.1 & 8.4 & 97.7 & 3.9 & $0.000^{*}$ \\
\hline Surgical pain management & 6.9 & 14.5 & 99.2 & 0.4 & $0.000^{*}$ & 29.5 & 17.5 & 94.1 & 12.2 & $0.000^{*}$ & 17.4 & 20.1 & 96.7 & 4.8 & $0.000^{*}$ \\
\hline Phantom pain management & 2.5 & 11.2 & 99.2 & 0.4 & $0.000^{*}$ & 12.7 & 14.4 & 95.4 & 6.1 & $0.000^{*}$ & 4.8 & 11.4 & 85.5 & 13.1 & $0.000^{*}$ \\
\hline Wound care & 7.5 & 18.3 & 99.3 & 0.4 & $0.000^{*}$ & 34.2 & 18.1 & 97.6 & 3.6 & $0.000 *$ & 25.6 & 14.6 & 98.0 & 3.2 & $0.000^{*}$ \\
\hline Mobility \& & 7.5 & 18.3 & 97.6 & 7.2 & $0.000^{*}$ & 15.9 & 16.0 & 96.0 & 3.2 & $0.000 *$ & 6.4 & 11.6 & 94.2 & 4.4 & $0.000^{*}$ \\
\hline $\begin{array}{l}\text { Control of blood glucose } \\
\text { level (BGL) }\end{array}$ & 39.7 & 17.3 & 98.5 & 3.2 & $0.000^{*}$ & 44.3 & 15.9 & 99.2 & 0.4 & $0.000^{*}$ & 19.3 & 14.5 & 97.4 & 3.7 & $0.000^{*}$ \\
\hline Discharge plan \& follow up & 7.0 & 12.6 & 97.9 & 3.4 & $0.000^{*}$ & 15.5 & 13.9 & 97.9 & 3.4 & $0.000 *$ & 10.5 & 11.0 & 97.9 & 3.4 & $0.000^{*}$ \\
\hline $\begin{array}{l}\text { Prevention of general } \\
\text { complications: } \\
\text { - Fall \& trauma } \\
\text { prevention } \\
\end{array}$ & 0.0 & 0.0 & 98.8 & 2.3 & $0.000 *$ & 4.0 & 8.7 & 98.2 & 3.3 & $0.000^{*}$ & 1.4 & 4.3 & 92.4 & 8.6 & $0.000^{*}$ \\
\hline - Skin breakdown & 0.6 & 2.7 & 99.2 & 0.4 & $0.000^{*}$ & 3.8 & 6.0 & 99.2 & 0.4 & $0.000 *$ & 0.6 & 2.7 & 99.2 & 0.4 & $0.000^{*}$ \\
\hline $\begin{array}{l}\text { Prevention of wound } \\
\text { complications: } \\
\text { - Hemorrhage } \\
\end{array}$ & 6.3 & 19.7 & 98.2 & 3.2 & $0.000 *$ & 35.1 & 17.9 & 98.7 & 2.3 & $0.000 *$ & 14.3 & 20.5 & 98.7 & 2.3 & $0.000^{*}$ \\
\hline - Edema & 1.3 & 5.6 & 98.7 & 2.5 & $0.000^{*}$ & 10.0 & 14.4 & 98.7 & 2.5 & $0.000 *$ & 1.3 & 5.6 & 98.7 & 2.5 & $0.000^{*}$ \\
\hline - Infection & 8.9 & 18.2 & 99.2 & 0.4 & $0.000^{*}$ & 37.1 & 17.6 & 99.2 & 0.4 & $0.000 *$ & 28.1 & 14.0 & 99.2 & 0.4 & $0.000^{*}$ \\
\hline - Stump contracture & 7.5 & 15.7 & 99.2 & 0.4 & $0.000^{*}$ & 6.6 & 13.5 & 99.2 & 0.4 & $0.000^{*}$ & 0.0 & 0.0 & 99.2 & 0.4 & $0.000^{*}$ \\
\hline
\end{tabular}


Table (5): Stump healing Assessment for Postoperative Diabetic Patients with Lower Limb Amputation in both control and study groups

\begin{tabular}{|c|c|c|c|c|c|}
\hline \multirow{3}{*}{ Stump healing } & \multicolumn{4}{|c|}{ Group } & \multirow{3}{*}{$\mathbf{p}$} \\
\hline & \multicolumn{2}{|c|}{ Control } & \multicolumn{2}{|c|}{ Study } & \\
\hline & No & $\%$ & No & $\%$ & \\
\hline \multicolumn{5}{|l|}{ The 2 nd week of follow up } & \multirow{3}{*}{$x^{2} \mathrm{p}=0.027^{*}$} \\
\hline - Completely healed & 7 & 35.0 & 14 & 70.0 & \\
\hline - Incompletely healed & 13 & 65.0 & 6 & 30.0 & \\
\hline Mean \pm SD & \multicolumn{2}{|c|}{$13.9 \pm 4.2$} & \multicolumn{2}{|c|}{$8.4 \pm 2.6$} & $0.000 *$ \\
\hline \multicolumn{5}{|l|}{ The 3rd week of follow up } & \multirow{3}{*}{$\chi^{2} p=0.011^{*}$} \\
\hline - Completely healed & 7 & 35.0 & 15 & 75.0 & \\
\hline - Incompletely healed & 13 & 65.0 & 5 & 25.0 & \\
\hline Mean \pm SD & \multicolumn{2}{|c|}{$13.4 \pm 4.2$} & \multicolumn{2}{|c|}{$8.5 \pm 2.9$} & $0.000 *$ \\
\hline \multicolumn{5}{|l|}{ The 4th week of follow up } & \multirow{3}{*}{$0.001 *$} \\
\hline - Completely healed & 7 & 35.0 & 17 & 85.0 & \\
\hline - Incompletely healed & 13 & 65.0 & 3 & 15.0 & \\
\hline Mean \pm SD & \multicolumn{2}{|c|}{$13.5 \pm 4.5$} & \multicolumn{2}{|c|}{$8.3 \pm 2.8$} & $0.000 *$ \\
\hline \multicolumn{5}{|l|}{ The 5th week of follow up } & \multirow{3}{*}{$0.001 *$} \\
\hline - Completely healed & 7 & 35.0 & 17 & 85.0 & \\
\hline - Incompletely healed & 13 & 65.0 & 3 & 15.0 & \\
\hline Mean \pm SD & \multicolumn{2}{|c|}{$13.3 \pm 4.6$} & \multicolumn{2}{|c|}{$8.4 \pm 3.1$} & $0.000 *$ \\
\hline \multicolumn{5}{|l|}{ The 6th week of follow up } & \multirow{3}{*}{$0.001 *$} \\
\hline - Completely healed & 7 & 35.0 & 17 & 85.0 & \\
\hline - Incompletely healed & 13 & 65.0 & 3 & 15.0 & \\
\hline Mean \pm SD & \multicolumn{2}{|c|}{$13.3 \pm 4.6$} & \multicolumn{2}{|c|}{$8.4 \pm 3.1$} & $0.000 *$ \\
\hline
\end{tabular}

$\chi^{2} \mathrm{p}$ : P value based on Chi square probability

$* \mathrm{P}<0.05$ (significant) 
Table (6): Clinical Pathway Variances Assessment (CPVA) for Perioperative Diabetic Patients with Lower Limb Amputation for study group

\begin{tabular}{|l|c|c|c|c|c|c||}
\hline \multirow{2}{*}{ Variance items } & \multicolumn{2}{|c|}{$\begin{array}{c}\text { Not } \\
\text { applicable }\end{array}$} & \multicolumn{2}{c|}{$\begin{array}{c}\text { Done } \\
\text { inadequate }\end{array}$} & \multicolumn{2}{c|}{$\begin{array}{c}\text { Done } \\
\text { adequate }\end{array}$} \\
\cline { 2 - 8 } & No & $\%$ & No & $\%$ & No & $\%$ \\
\hline 1- General assessment & 0 & 0.0 & 0 & 0.0 & 20 & 100.0 \\
\hline 2- Vital signs assessment & 0 & 0.0 & 3 & 15.0 & 17 & 85.0 \\
\hline 3- Anthropometric Assessment & 7 & 35.0 & 4 & 20.0 & 9 & 45.0 \\
\hline 4- Both lower limbs assessment & 0 & 0.0 & 3 & 15.0 & 17 & 85.0 \\
\hline 5- Diagnostic studies & 0 & 0.0 & 3 & 15.0 & 17 & 85.0 \\
\hline 6- Medications & 0 & 0.0 & 3 & 15.0 & 17 & 85.0 \\
\hline 7- Psychological care & 0 & 0.0 & 0 & 0.0 & 20 & 100.0 \\
\hline 8- Health education & 0 & 0.0 & 0 & 0.0 & 20 & 100.0 \\
\hline 9-Nursing interventions of surgical pain & 3 & 15.0 & 0 & 0.0 & 17 & 85.0 \\
\hline $\begin{array}{l}\text { 10- Nursing interventions of altered } \\
\text { sensory perception }\end{array}$ & 0 & 0.0 & 0 & 0.0 & 20 & 100.0 \\
\hline 11- Dressing and wound care & 0 & 0.0 & 3 & 15.0 & 17 & 85.0 \\
\hline 12-Mobility and exercises & 0 & 0.0 & 0 & 0.0 & 20 & 100.0 \\
\hline 13- Prevention of complications & 0 & 0.0 & 3 & 15.0 & 17 & 85.0 \\
\hline 14- Control of blood glucose level & 0 & 0.0 & 3 & 15.0 & 17 & 85.0 \\
\hline 15- Discharge plane and follow up & 0 & 0.0 & 3 & 15.0 & 17 & 85.0 \\
\hline \hline
\end{tabular}


Table (7): Comparison between Perioperative Assessment for Patients with Diabetic Lower Limb Amputation in both control and study groups for total patients' satisfaction with caring process

\begin{tabular}{|c|c|c|c|c|c|}
\hline \multirow{3}{*}{ Satisfaction total } & \multicolumn{4}{|c|}{ Group } & \multirow{3}{*}{$F E P$} \\
\hline & \multicolumn{2}{|c|}{ Control } & \multicolumn{2}{|c|}{ Study } & \\
\hline & No & $\%$ & No & $\%$ & \\
\hline Dissatisfied & 17 & 85.0 & 0 & 0.0 & \multirow{4}{*}{$0.000^{*}$} \\
\hline Neutral & 3 & 15.0 & 0 & 0.0 & \\
\hline Satisfied & 0 & 0.0 & 15 & 75.0 & \\
\hline Very satisfied & 0 & 0.0 & 5 & 25.0 & \\
\hline Range & \multicolumn{2}{|c|}{$27-45$} & \multicolumn{2}{|c|}{$51-75$} & \multirow{2}{*}{$14.3(0.000)^{* \#}$} \\
\hline Mean \pm SD & \multicolumn{2}{|c|}{$33.9 \pm 5.6$} & \multicolumn{2}{|c|}{$60.2 \pm 6.0$} & \\
\hline
\end{tabular}

FEP: P value based on Fisher exact probability 


\section{References}

1. Buttaro $T$, Trybulski J, Bailey $P$, Sandburg J. Primary Care: A Collaborative Practice. $3^{\text {rd }}$ ed. Philadelphia: Mosby; 2008; 1098-113.

2. National Institute for Health and Clinical Excellence. Diabetic Foot Problems. London: NICE; 2012; 4-17. Available at: http://www.nice.org.uk. (Retrieved on: 18/7/2013).

3. Carrington A, Abbott C, Griffiths J, Jackson N, Johnson S, Kulkarnt J, Van Ross E, Boulton A. Peripheral Vascular and Nerve Function Associated with Lower Limb Amputation in People with and Without Diabetes. Clinical Science 2001; 101(3): 261-6.

4. Wells C. Orchestrating Healing: A Grounded Theory of Registered Nurses Caring for Patients with Diabetic Foot ulcers. University of Calgary, Faculty of Nursing: Published DSN dissertation. 2011.

5. Gils C, Wheeler L, Mellstrom M, Brinton E, Mason S, Wheeler G. Amputation Prevention by Vascular Surgery and Podiatry Collaboration in High-Risk Diabetic and non Diabetic Patients. Diabetes Care 1999; 22 (5): 678- 83.

6. Lipsky B, Berendt A, Cornia P, Pile J, Peters E, Armstrong D, Deery G, Embil J, Joseph W, Karchmer A, Pinzur M, Senneville E. 2012 Infectious Diseases Society of America Clinical Practice Guideline for the Diagnosis and Treatment of Diabetic Foot Infections. Clinical Infectious Diseases 2012; 54(15): 132- 7.

7. Corbett C. Practical Management of Patients with Painful Diabetic Neuropathy. Diabetes Educ 2005; 31(4):526-32.
8. Gerry R, Singhan K, Neil B, Alison W, Anne R. Are We Underestimating Diabetes-Related Lower-Extremity Amputation Rates? Results and Benefits of the First Prospective Study. Diabetes Care 2004; 27(8): 1892-6.

9. Fahey V. Vascular Nursing. $3^{\text {rd }}$ ed. USA: Saunders Company; 1999; 218 422.

10. Finkel A. Lower Extremity Amputation. Brigham and Women's Hospital Department of Rehabilitation Services Physical Therapy. 2011; 1-46.

11. MacKay D, Miller A. Nutritional Support for Wound Healing. Alternative Medicine Review 2003; 8(4): 359- 77.

12. Rothrock J, Smith D, McEwen D. Alexander's Care of the Patient in Surgery. $12^{\text {th }}$ ed. USA: Mosby; 2003; 290-6.

13. Pino A, Taghva S, Chapman C, Bowker J. Lower-limb Amputations in Patients with Diabetes Mellitus 2011; 34(12): 885-92.

14. Panella M, Marchisio S, Stanislao F. Reducing Clinical Variations with Clinical Pathways: Do Pathways Work? International Journal for Quality in Health Care 2003; 15(6): 509-21.

15. Young T. The healing of Amputation Wounds. Nursing Standard ProQuest Central 2004; 18(45): 74-8.

16. Monahan F, Sands J, Neighors M, Marek J, Green C. Phipps' MedicalSurgical Nursing Health and Illness Perspectives. $8^{\text {th }}$ ed. USA: Mosby; 2007; 4-1123.

17. Smeltzer S, Bare B, Hinkle J, Cheever K. Brunner \& Suddarth's Text Book of Medical Surgical Nursing. $10^{\text {th }}$ ed. New Delhi: Lippincott Williams \& Wilkins, 2005; 9-2201. 
18. Gray J. Thinking about Adoption. Journal of Integrated Care Pathways 2005; 9(2): 47-50.

19. Mann E, Carr E. Pain Management. Philadelphia: Blackwell 2006; 15-20.

20. Warden V, Hurley A, Volicer L. Development and Psychometric Evaluation of the Pain Assessment in Advanced Dementia (PAINAD) Scale. Journal of the American Medical Directors Association 2003; 4(1):9-15.

21. Hawker G, Mian S, Kendzerska T, French M. Measures of Adult Pain. Arthritis Care \& Research 2011; 63(11):S240-S52.

22. Teunissen S, Wesker W, Kruitwagen C, Haes H, Voest E, Graeff A. Symptom Prevalence in Patients with Incurable Cancer: A Systematic Review. Journal of Pain and Symptom Management 2007; 34(1): 94-104.

23. National consensus project for quality palliative care. Clinical Practice Guidelines for Quality Palliative Care. $3^{\text {th }}$ ed. Pittsburgh Pennsylvania USA: National consensus project for quality palliative care 2013; 13-32.

24. Salisbury C, Burgess A, Lattimer V, Heaney D, Walker J, Turnbull J, Smith H. Developing a Standard Short Questionnaire for the Assessment of Patient Satisfaction Without- of- Hours Primary Care, Family Practice 2005; 22(5): 560-9.

25. Abd El-Aziz E. The Effect of the Application of Clinical Pathway on Postoperative Outcomes of Patients Undergoing Percutaneous

Nephrolithotomy. Alexandria University, Faculty of Nursing: Unpublished DSN dissertation. 2011.

26. May b. Amputations and Prosthetics A Case Study Approach. $2^{\text {nd }}$ ed. Augusta, Georgia 2002; 11-243.
27. National consensus project for quality palliative care. Clinical Practice Guidelines for Quality Palliative Care. $2^{\text {nd }}$ ed. Pittsburgh Pennsylvania USA: National consensus project for quality palliative care 2009 ; 15-63.

28. Hickam D, Weiss J, Guise J, Buckley D, Motu'apuaka M, Graham E, Wasson N, Saha S. Outpatient Case Management for Adults With Medical Illness and Complex Care Needs. Agency for Healthcare Research and Quality 2013; No. 13: 1-93.

29. American Dietetic Association. Manual of Clinical Dietetics. $6^{\text {th }}$ ed. Chicago, IL: American Dietetic Association; 2006.

30. Mozumdar A, Roy S. Method for Estimating Body Weight in Persons with Lower-Limb Amputation and its Implication for Their Nutritional Assessment. Am J Clin Nutr 2004; 80(4): $868-75$

31. Giummarraa M, Moseley L. Phantom Limb Pain and Bodily Awareness: Current Concepts and Future Directions. Current Opinion in Anesthesiology 2011; 24(5): 524-31.

32. Monga T, Grabois M. Pain Management in Rehabilitation. New York: Demos Medical publishing 2002; 191-203.

33. Connell W. Ethics Tool Database. USA: Boston College School of Nursing 2013; 14-5.

34. Gould D. Information Point: Visual Analogue Scale. Journal of Clinical Nursing 2001; 10(5): 697-706.

35. Abbreviated Report of a WHO Consultation Use of Glycated Hemoglobin (HbA1c) in the Diagnosis of Diabetes Mellitus 2011.

36. Health Service Executive. National best practice and evidence based guidelines for wound management. Ireland 2009; 
22-9. Available at: http://www.hse.ie. Retrieved on: (25/1/2014).

37. Chaisakchatree V. Tools to Measure Wound Healing. Siriraj Hospital 2009.

38. Taylor C. Foot Assessments in Type 2 Diabetes: An Evidence-Based Practice Approach. University of South Carolina, College of Nursing: Published DSN dissertation. 2008.

39. Judge N. Neurovascular Assessment. Nursing Standard 2007; 21(45): 39-44.

40. Leigheb F, Vanhaecht K, Sermeus W, Lodewijckx C, Deneckere S, Boonen S, Boto P, Mendes R, Panella M. The Effect of Care Pathways for Hip Fractures: A Systematic Review. Calcif Tissue journal 2012; 18(6): 1-14

41. Berghe G, Wouters P, Weekers F, Verwaest C, Bruyninckx F, Schetz M, Vlasselaers D, Ferdinande P, Lauwers P, Bouillon R. Intensive Insulin Therapy in Critically Ill Patients. New England Journal of Medicine 2001; 345(19):1359-67.

42. Fraser C. The Importance of Investigating the Presence of Hyperglycemia in Individuals with Wounds. Wound Care Canada 2007; 5 (2): $20-1$.

43. Posthauer M. Diet, Diabetes, and Wound Management. How Important is Glycemic Control? The Nurse Practitioner 2004; 29(8): 318 -20.

44. Carson J, Scholz P, Chen A, Peterson E, Gold J, Schneider S. Diabetes Mellitus Increases Short-Term Mortality and Morbidity in Patients Undergoing Coronary Artery Bypass Graft Surgery. Journal of the American College of Cardiology 2002; 40 (3):418-23.

45. Choong $\mathrm{P}$, Langford A, Dowsey M, Santamaria N. Clinical Pathway for Fractured Neck of Femur: A Prospective Controlled Study. The
Medical Journal of Australia 2000; 172(9): 423-7.

46. Calland F, Tanaka K, Foley E, Bovbjerg V, Markey D, Blome S, Minasi J, Hanks J, Moore M, Young J, Jones S, Schirmer B, Adams R. Outpatient Laparoscopic Cholecystectomy: Patient Outcomes After Implementation of a Clinical Pathway. Annals of Surgery 2001; 233(5): 704-15.

47. World Health Organization. Adherence to Long-Term Therapies-Evidence for Action 2003. Available at: http://www.who.int/chronic conditions/ en/adherence_report.pdf.

48. Kalogianni A. Factors Affect in Patient Adherence to Medication Regimen. Health Science Journal 2011; 5(3): 1578.

49. Dealey C. The Care of Wounds: A Guide for Nurses. $3^{\text {rd }}$ ed. Oxford: Blackwell Publishing; 2005. 13-55.

50. Ban A, Ismail A, Harun R, Abdul Rahman A, Sulung S, Mohamed A. Impact of Clinical Pathway on Clinical Outcomes in the Management of COPD Exacerbation. BMC Pulmonary Medicine 2012; 12(27): 1-8.

51. Dean A. Clinical Pathways: Effects on Practice, Outcomes, and Costs. American Family Physician 2010; 82(11): 1338- 40.

52. Frank C, Marshall D, Faris P, Comm C. Improving Access to Hip and Knee Replacement and its Quality by Adopting a New Model of Care in Alberta. Canadian Medical Association Journal 2011; 183(6): E347 - 50.

53. El Baz N, Middel B, Van Dijk J, Boonstra P, Reijneveld S. Coronary Artery Bypass Graft (CABG) Surgery Patients in a Clinical Pathway Gained Less in Health-related Quality of Life as Compared With Patients Who Undergo 
CABG in a Conventional-Care Plan. Journal of Evaluation in Clinical Practice 2009; 15: 498-505.

54. Roberts H, Pickering R, Onslow E, Clancy M, Powell, Roberts A, Hughes K, Coulson D, Bray J. The Effectiveness of Implementing a Care Pathway for Femoral Neck Fracture in Older People: a Prospective Controlled Before and After Study. Age and aging 2004; 33(2): 178-84.

55. Khowaja K. Integrated Clinical Pathway of Transurethral Resection of the Prostate: Impact on Clinical Quality, Cost, and Patient and Staff Satisfaction, published Doctoral thesis, Australia: School of Nursing: University of Ballarat 2003.

56. Beaupre L, Cinats J, Senthilselvan A, Scharfenberger A, Johnston W, Saunders D. Does Standardized Rehabilitation and Discharge Planning Improve Functional Recovery in Elderly Patients With Hip Fracture? Archives of Physical Medicine and Rehabilitation 2005; 86(12): 2231-9.

57. Sulch D, Perez I, Melbourn A, Kalra L. Randomized Controlled Trial of Integrated (managed) Care Pathway for Stroke Rehabilitation. Stroke 2000; 31(8): 1929-34.
58. Global Institute for Emerging Healthcare Practices. Preventing Hospital Readmissions: The First Test Case For Continuity of Care 2012

59. Van Dam P, Verheyden G, Sugihara A, Trinh X, Herman Mussele V, Wuyts H, Verkinderen L, Hauspy J, Vermeulen P, Dirix L. A Dynamic Clinical Pathway for the Treatment of Patients with Early Breast Cancer is a Tool for Better Cancer Care: Implementation and Prospective Analysis Between 20022010. World Journal of Surgical Oncology 2013; 11(70): 1-10.

60. Jon H, Moon I, Park H, Kim N, Yang S. The Effects of the Critical Pathway for Inguinal Hernia Repair. Yonsei Medical Journal 2003; 44(1):81-8.

61. Smith T, Hillner B. Ensuring Quality Cancer Care by the Use of Clinical Practice Guidelines and Critical Pathways. Journal of Clinical Oncology 2001; 19(11) 2886-97.

62. Abbass H. The Effect of Implementation A Clinical Pathway on Health Outcomes of Patients Undergoing Percutaneous Coronary Intervention. Alexandria University, Faculty of Nursing: Unpublished DSN dissertation. 2014. 